\title{
An Ounce of Prevention: A Review of the Most Common Errors in OB/GYN Ultrasound Leading to Litigation and How to Avoid Them
}

\author{
Timothy J Rafael ${ }^{1}$, Frank A Chervenak ${ }^{2}$
}

\begin{abstract}
The use of ultrasound in the field of Obstetrics and Gynecology (OB/GYN) has become ubiquitous. As OB/GYN is a higher-risk specialty pertaining to the risk of litigation, it is no surprise that lawsuits involving ultrasound in OB/GYN are not uncommon. Errors in ultrasound are not rare, with certain types of errors seemingly more prone to litigation. Upon examination of the past 40 years of literature, it appears that the most frequent types of errors fall into one of three categories: (1) technical/procedural, (2) perception/interpretation, and (3) communication/documentation. The aim of this review is to break down the types of ultrasound errors that fall into these categories and utilize "take-home" summary points as a way of strategizing the prevention of these types of errors. Among other methods, these summary points emphasize adequate ultrasound training and continuing education, knowledge of the guidelines, ample patient counseling, effective communication with referring providers, and meticulous documentation. Upon completion of this review, it is hoped that the reader has an appreciation of the steps a practitioner can take to avoid these types of lawsuits in the future.
\end{abstract}

Keywords: Anomaly, Congenital heart malformations, Down syndrome, Prevention, Re-scanning, Sonography, Ultrasound.

Donald School Journal of Ultrasound in Obstetrics and Gynecology (2021): 10.5005/jp-journals-10009-1817

\section{INTRODUCTION}

Over the past 50 years, the invention and development of ultrasound have revolutionized the field of Obstetrics and Gynecology (OB/GYN). As a diagnostic tool in the area of obstetrics, it has allowed providers to accurately confirm and date intrauterine pregnancies, evaluate fetal anatomy, and assess fetal growth and well-being, to name merely a few of its many uses. Ultrasound's portability, ease of use, overall safety, and ability to provide real-time results are the reasons why nearly all OB/GYN offices have at least one ultrasound machine. For a patient to go through an entire pregnancy without a single ultrasound examination is now almost unheard of.

As the diagnostic capabilities of ultrasound have improved over the last five decades, so has the expectation of patients for satisfactory pregnancy outcomes. Unfortunately, despite many unsatisfactory outcomes being inevitable, given the high expectations of the general public, patients and their families may look to find fault in their provider's management of the pregnancy. ${ }^{1}$ Despite reasonable progress made in the area of tort reform, and decreases in the rate of malpractice claims paid on behalf of physicians in the United States, OB/GYN remains one of the more high-risk specialties: this includes not only the number of lawsuits but also the percentage of cases resulting in paid claims. ${ }^{2-4}$ As many as $5-6 \%$ of OB/GYN-related lawsuits involve obstetric ultrasound and prenatal diagnosis, in and of itself, not an insignificant number, ${ }^{5}$ in that although only a small proportion of routine fetal examinations by ultrasound result in legal claims or settlements, the financial, social, and emotional tolls to the physician can be significant. ${ }^{6}$ This has led to the inevitable practice of defensive medicine, where excessive tests or studies may be ordered, or practices not accepting patients perceived as potentially litigious. ${ }^{7}$
${ }^{1}$ Department of Obstetrics and Gynecology, Division of Maternal-Fetal Medicine, North Shore University Hospital-Zucker School of Medicine at Hofstra/Northwell Manhasset, New York, USA

${ }^{2}$ Department of Obstetrics and Gynecology, Lenox Hill HospitalZucker School of Medicine at Hofstra/Northwell, New York, USA

Corresponding Author: Timothy J Rafael, Department of Obstetrics and Gynecology, Division of Maternal-Fetal Medicine, North Shore University Hospital-Zucker School of Medicine at Hofstra/Northwell Manhasset, New York, USA, Phone: +1-516-562-2862, e-mail: trafael@northwell.edu

How to cite this article: Rafael TJ, Chervenak FA. An Ounce of Prevention: A Review of the Most Common Errors in OB/GYN Ultrasound Leading to Litigation and How to Avoid Them. Donald School J Ultrasound Obstet Gynecol 2021;15(4):380-386.

Source of support: Nil

Conflict of interest: None

With the nature of the field, along with the high expectations from the general public, litigation may be inevitable in the career of an $\mathrm{OB} / \mathrm{GYN}$. To establish negligence in a lawsuit, the plaintiff must show that there was (1) a duty recognized by law, (2) a breach of that duty in that there was a failure on the part of the physician to meet what was considered to be the standard of care at the time the treatment was rendered, (3) a causal relationship between the treatment and the resulting injury, and (4) actual loss or damage to the plaintiff. ${ }^{8}$ That said, errors can and have been made involving ultrasound. Beginning with Dr. Roger Sanders and his work elucidating medicolegal matters in the field of ultrasound, ${ }^{9}$ our aim with this review was to examine the literature over the past 40 years, and to highlight the most common errors in $\mathrm{OB} / \mathrm{GYN}$ ultrasound leading to litigation. For the most part, errors can be classified into one of the following three categories:

(OTheAuthor(s). 2021 Open Access This article is distributed under the terms of the Creative Commons Attribution 4.0 International License (https://creativecommons. org/licenses/by-nc/4.0/), which permits unrestricted use, distribution, and non-commercial reproduction in any medium, provided you give appropriate credit to the original author(s) and the source, provide a link to the Creative Commons license, and indicate if changes were made. The Creative Commons Public Domain Dedication waiver (http://creativecommons.org/publicdomain/zero/1.0/) applies to the data made available in this article, unless otherwise stated. 
- Technical/procedural errors

- Perception/interpretation errors

- Communication/documentation errors

"Take home" points will be used in each section, for summary purposes. By understanding how and when these errors can occur in the ultrasound process, practitioners can protect themselves through meticulous practice and prevention.

\section{Technical/Procedural Errors}

As ultrasound usage gained traction in the 1980s, there were calls for national and international guidelines as a way to standardize care. ${ }^{10}$ Throughout the years since there have been many iterations of guidelines set forth by the American College of OB/GYN (ACOG) and the American Institute for Ultrasound in Medicine (AIUM). Of note, guidelines put forth by these organizations do not necessarily establish the standard of care introduced at trial, but the ultrasound practitioner should be aware of these recommendations by the ACOG and AIUM. These organizations have published recommendations regarding guidelines, instrumentation and safety, indications, documentation, examination content, and quality control. Chief among these guidelines is that ultrasound should never be performed without a clear indication, as a physician is not obligated to perform an ultrasound in a low-risk patient without an indication. ${ }^{8}$ That said, a potential area of litigation involves not performing an ultrasound when one is indeed indicated (for example, confirm a suspected demise before dilation and curettage, small for dates, follow up placenta previa, previous ectopic pregnancy, before methotrexate administration). ${ }^{11,12}$ Indications for a first-trimester ultrasound examination are listed in Box $1^{13}$ For the second and third trimesters, the ACOG and AIUM, along with the American College of Radiology, the National Institute of Child Health and Human Development (NICHD), the Society for Maternal-fetal Medicine (SMFM), and the Society of Radiologists in Ultrasound have adopted the following uniform terminology for performing various ultrasound examinations: standard, limited, and specialized. ${ }^{14}$ Although the failure to follow the accepted guidelines does not automatically result in litigation, failure to adhere to these guidelines in the event of an adverse outcome makes a case that much more difficult to defend, as these guidelines may be used in an attempt to establish a standard of care: $:^{15}$

Box 1: Indications for a first-trimester ultrasound examination ${ }^{13}$

Indications for sonographic examination if the first trimester include, but are not limited to:

- Confirmation of the presence of an intrauterine pregnancy

- Confirmation of cardiac activity

- Estimation of gestational age

- Diagnosis or evaluation of multiple gestations, including determination of chorionicity

- Evaluation of a suspected ectopic pregnancy

- Evaluation of the cause of vaginal bleeding

- Evaluation of pelvic pain

- Evaluation of suspected gestational trophoblastic disease

- Assessment for certain fetal anomalies, such as anencephaly

- Measurement of the NT when part of a screening program for fetal aneuploidy

- Imaging as an adjunct to chorionic villus sampling, embryo transfer, and localization and removal of an intrauterine device

- Evaluation of maternal pelvic masses and/or uterine abnormalities.
- Standard (Box 2): $:^{13}$ includes an evaluation of fetal presentation and number, amniotic fluid volume, cardiac activity, placental position, fetal biometry, and an anatomic survey. The maternal cervix and adnexa should be examined when clinically appropriate and when technically feasible.

- Limited: performed when a specific question requires investigation (for example, confirm fetal heart activity in a patient with an obstetrical issue such as bleeding, confirm fetal presentation, check placental location, etc.).

- Specialized (Table 1): $:^{16}$ more extensive than the standard examination (for example, detailed fetal anatomy ultrasound when there is an increased risk of fetal anatomical malformation, Doppler studies, biophysical profile, fetal echocardiogram, etc.). These examinations are performed only by those practitioners with formalized training in these areas.

Physicians who perform and/or interpret ultrasound examinations should be licensed medical practitioners who have an understanding of the above guidelines and be trained to interpret OB/GYN ultrasounds. While many physicians and providers may feel comfortable reading and interpreting a routine bedside ultrasound, from a medical-legal standpoint, they should first have completed an accredited residency and/or fellowship program, and demonstrate evidence of a required number of AMA PRA Category 1 Credits $^{\mathrm{T}}$. Maintenance of competence and continuing medical education must also be demonstrated. As further details of these criteria are beyond the scope of this review, we encourage the reader to visit the AIUM website for further clarification. ${ }^{17}$ While individuals cannot be accredited by the AIUM, ultrasound facilities can. Practices can be accredited for ultrasound in obstetrics, gynecology, or both. The process involves the review

Box 2: Indications for a standard second- and third-trimester ultrasound examination $^{13}$

Indications used to assess fetal anatomy and biometry include, but are not limited to:

- Screening for fetal anomalies

- Evaluation of fetal anatomy

- Estimation of gestational age

- Evaluation of suspected multiple gestation

- Evaluation of cervical length

- Evaluation of fetal growth

- Evaluation of a significant discrepancy between uterine size and clinical dates

- Determination of fetal presentation

- Evaluation of fetal well-being

- Suspected amniotic fluid abnormalities

- Evaluation of premature rupture of membranes and/or premature labor

- Evaluation of vaginal bleeding

- Evaluation of abdominal or pelvic pain

- Suspected placental abruption

- Suspected fetal death

- Follow-up evaluation of a fetal anomaly

- Evaluation/follow-up of placental appearance and location, including suspected placenta previa, vasa previa, and abnormally adherent placenta

- Adjunct to amniocentesis or other procedure

- Adjunct to external cephalic version

- Evaluation of suspected gestational trophoblastic disease

- Evaluation of a pelvic mass

- Suspected uterine anomalies. 
Table 1: Contents of a standard second- and third-trimester diagnostic obstetric ultrasound examination - CPT Code $76811^{16}$

\begin{tabular}{|c|c|c|}
\hline Component & Standard & Detailed $^{*}$ \\
\hline Head and neck & $\begin{array}{l}\text { Lateral cerebral ventricles } \\
\text { Choroid plexus } \\
\text { Midline falx } \\
\text { Cavum septi pellucidi } \\
\text { Cerebellum } \\
\text { Cisterna magna }\end{array}$ & $\begin{array}{l}\text { 3rd ventricle } \\
\text { 4th ventricle } \\
\text { Lateral ventricular wall integrity, contour, ependymal lining } \\
\text { Cerebellar lobes, vermis, and cisterna magna } \\
\text { Corpus callosum } \\
\text { Integrity and shape of cranial vault } \\
\text { Brain parenchyma } \\
\text { Neck }\end{array}$ \\
\hline Face & Upper lip & $\begin{array}{l}\text { Profile } \\
\text { Nasal bone (15-22 weeks) } \\
\text { Coronal face (nose/lips/lens) } \\
\text { Palate, maxilla, mandible, and tongue } \\
\text { Ear position and size } \\
\text { Orbits }\end{array}$ \\
\hline $\begin{array}{l}\text { Chest } \\
\text { Heart } \\
\text { Thorax }\end{array}$ & $\begin{array}{l}\text { Cardiac activity } \\
\text { 4-chamber view } \\
\text { Left ventricular outflow tract } \\
\text { Right ventricular outflow tract } \\
\text { 3-vessel view (if technically feasible) } \\
\text { 3-vessel and trachea view (if technically feasible) }\end{array}$ & $\begin{array}{l}\text { Situs } \\
\text { Aortic arch } \\
\text { Superior and inferior venae cavae } \\
\text { Ductal arch } \\
\text { Interventricular septum } \\
\text { 3-vessel view } \\
\text { 3-vessel and trachea view } \\
\text { Lungs } \\
\text { Integrity of diaphragm } \\
\text { Ribs }\end{array}$ \\
\hline Abdomen & $\begin{array}{l}\text { Stomach (presence, size, and situs) } \\
\text { Kidneys } \\
\text { Urinary bladder } \\
\text { Cord insertion site into fetal abdomen } \\
\text { Umbilical cord vessel number }\end{array}$ & $\begin{array}{l}\text { Small and large bowel } \\
\text { Adrenal glands } \\
\text { Gallbladder } \\
\text { Liver } \\
\text { Renal arteries } \\
\text { Spleen } \\
\text { Integrity of abdominal wall }\end{array}$ \\
\hline Spine & $\begin{array}{l}\text { Cervical } \\
\text { Thoracic } \\
\text { Lumbar } \\
\text { Sacral spine }\end{array}$ & $\begin{array}{l}\text { Integrity of spine and overlying soft tissue } \\
\text { Shape, curvature, conus medullaris }\end{array}$ \\
\hline Extremities & $\begin{array}{l}\text { Legs } \\
\text { Arms } \\
\text { Hands } \\
\text { Feet }\end{array}$ & $\begin{array}{l}\text { Number, architecture, and position } \\
\text { Digits of hands and feet: number and position }\end{array}$ \\
\hline Genitalia & $\begin{array}{l}\text { In multiple gestations } \\
\text { When medically indicated }\end{array}$ & External genitalia \\
\hline Placenta & $\begin{array}{l}\text { Location } \\
\text { Relationship to internal os } \\
\text { Appearance } \\
\text { Placental cord insertion }\end{array}$ & $\begin{array}{l}\text { Masses } \\
\text { Accessory/succenturiate lobe with location of connecting } \\
\text { vascular supply to primary placenta and internal cervical os } \\
\text { Implantation site with evaluation for abnormal adherence }\end{array}$ \\
\hline Standard evaluation & $\begin{array}{l}\text { Fetal number } \\
\text { Presentation } \\
\text { Qualitative or semiquantitative estimate of amniotic } \\
\text { fluid }\end{array}$ & \\
\hline Maternal anatomy & $\begin{array}{l}\text { Cervix (transvaginal when indicated) } \\
\text { Uterus } \\
\text { Adnexa }\end{array}$ & \\
\hline Biometry & $\begin{array}{l}\text { Biparietal diameter } \\
\text { Head circumference } \\
\text { Femur length } \\
\text { Abdominal circumference } \\
\text { Fetal weight estimate }\end{array}$ & $\begin{array}{l}\text { Cerebellum } \\
\text { Inner and outer orbital diameters } \\
\text { Nuchal fold thickness (16-20 weeks) } \\
\text { Humerus } \\
\text { Ulna/radius } \\
\text { Tibia/fibula }\end{array}$ \\
\hline
\end{tabular}

*All of these elements may not be indicated in every detailed obstetric ultrasound examination. Obtaining additional elements not listed in the table may be warranted 
of ultrasound case studies, equipment use and maintenance, report generation, image storage, and ultrasonographer and physician qualifications. Practices that receive this accreditation have been shown to improve compliance with published standards and guidelines for the performance of ultrasound examinations, ${ }^{14}$ and by being accredited, this compliance is demonstrated to patients and if needed, to a third party. In addition, many insurance companies now require accreditation for reimbursement for services. The process for having a facility accredited by the AIUM is available online. ${ }^{18}$

It is vitally important to ensure the proper training and supervision of sonographers. While not mandatory, it would be preferable if sonographers are ARDMS ${ }^{\circ}$ certified, for the same reasons a practice should be accredited. In a busy clinical practice, oftentimes the ultrasound is performed by the sonographer, which is later read by an attending physician, who never actually sees the patient in person. While this is perfectly suitable in many situations, the physician must never forget that they remain liable for the sonographer and other advanced clinical providers who perform the ultrasounds. Everything, from the acquiring and storage of adequate images to the maintenance of standards and patient safety, ultimately are the responsibility of the physician reading the ultrasound-this employs the legal concept of "Respondeat Superior," where an employer is liable for the wrong of an employee if it was committed within the scope of employment. ${ }^{15,19,20}$ There are also practice parameters for the performance of limited obstetric ultrasound examinations by advanced clinical providers, to ensure those taking care of patients in lieu of the physician adhere to at least the minimum criteria. Healthcare providers and their teams should also understand their scopes of practice within the state where they are practicing. ${ }^{21}$

Above all else, maintaining patient safety is paramount. During early pregnancy, the ACOG suggests using an abdominal ultrasound transducer with a frequency of $5 \mathrm{MHz}$ or a transvaginal transducer with a frequency of 5-10 $\mathrm{MHz}$ to provide adequate resolution. Later in pregnancy, or in obese patients, using a lower-frequency transducer may become necessary to allow for adequate beam penetration. Documentation of this will be discussed later. Ultrasound images should be archived and easily accessible for later review. ${ }^{14}$ While ultrasound is generally accepted to be safe, there is always the possibility of identifying untoward effects in the future, so it is recommended to always adhere to the as-low-as-reasonably-achievable (ALARA) principle; it is important to ensure the thermal and mechanical indices ( $\mathrm{TI}$ and $\mathrm{MI}$, respectively) are set at the lowest machine settings that are compatible with acquiring the necessary diagnostic information, and limiting the routine use of Doppler when not indicated (for example, to check a fetal heart rate), when an M-mode or video clip would suffice. ${ }^{14,22}$ Ultrasound transducers are involved in direct patient contact, thus there is the possibility of microbial transmission if not properly cleaned. Transabdominal transducers should be cleaned with a disposable disinfectant spray/wipe or soap and water, while transvaginal probes require high-level disinfection. The U.S. Food and Drug Administration has published a list of approved high-level disinfectants for use in processing reusable medical devices. ${ }^{14}$

\section{"Take Home" Points}

- Know the current ultrasound guidelines

- Have clear indication(s) for examinations

- Physicians who interpret ultrasound should be properly trained
- Have ultrasound site certified by the AIUM

- Ensure proper training and supervision of sonographers

- Adequate image acquisition and storage

- Maintain patient safety

- Maintenance of ultrasound equipment and standards.

\section{Perception/Interpretation Errors}

A perception error occurs when an ultrasound abnormality is missed during the initial interpretation; upon review of the images in retrospect, it can be visualized. An interpretation error happens when a finding or abnormality is visualized at the time of the initial examination but is not correctly interpreted. ${ }^{15}$ Litigation in this particular area has become more prevalent over the years; ultrasound equipment has become more widespread and sophisticated, clearer images have become somewhat easier to interpret, and expectations of the ability of diagnostic ultrasounds to aid in the diagnosis of even the smallest fetal anomalies have become higher. While in the 1980 s, the highest volume of litigation involved missed ectopic pregnancies, nowadays the majority of lawsuits are for missed fetal anomalies. ${ }^{11}$ Perception/Interpretation errors now account for the majority of ultrasound-related litigation, with undiagnosed fetal congenital anomaly accounting for the single most frequent dispute. ${ }^{23}$ Fortunately or unfortunately, this is not limited to the specialty of OB/GYN per se, as the radiological literature in general cites "failure to diagnose" as one of the more common etiologies behind a malpractice claim. ${ }^{24}$

Perception and/or interpretation errors can lead to what's referred to as "wrongful life" litigation. Cases such as these are brought about by families of children born with congenital malformations and/or genetic syndromes that were not detected during the antenatal period. If they had been diagnosed prenatally, it is argued, the patients involved would likely have exercised their right to terminate said pregnancy. ${ }^{25}$ The financial compensation sought in these cases seeks to recompense the family for the financial and emotional costs that can be associated with giving birth to, and raising, a physically or neurologically disabled child. Lawsuits such as these had originally been confined to laboratories and/or providers for misreading or misinterpreting laboratory results in cases of Down Syndrome or other genetically inherited diseases (e.g., Tay-Sachs); more recently the vast majority of these types of cases involve potential perception/interpretation errors during the prenatal ultrasound. ${ }^{26}$ Other litigation contends that a missed diagnosis was a significant or contributing factor involving negligent obstetric care that resulted in damages to the plaintiff infant or mother. ${ }^{8}$ What must be kept in mind is that ultrasound as an imaging modality is not incredibly sensitive to detect all anomalies. In a review of 36 studies comprising more than 900,000 fetuses, an overall sensitivity of approximately $40 \%$ for detecting fetal anomalies was noted, with a range of $15-80 \% .{ }^{27}$ Detection rates do tend to be higher at tertiary care referral centers, with some series quoting sensitivity and specificity rates of 88 and $99 \%$, respectively. ${ }^{28}$ The take-home message to physicians and sonographers alike is this: even on our best days, we are not perfect, and the sensitivity of ultrasound will never approach $100 \%$. How we convey this limited sensitivity to patients will be discussed in the next section.

So in trying one's best to avoid perception and/or interpretation errors, what can be done? Firstly, when appropriate, the value of the physician re-scanning the patient after the sonographer obtains 
their images cannot be overstated. ${ }^{29}$ There is only so much one can learn about the embryo or fetus with still-images, or even cine clips, that are obtained by the sonographer only. Especially in the event of a possible anomaly, there can be invaluable information obtained by adopting a "hands-on" approach, and it can provide the patient with the reassurance that the physician thoroughly evaluated them. Another method to possibly avert such errors on a detailed anatomy ultrasound, for example, would be to have patients return at a future date for follow-up imaging (e.g., 1-2 weeks) to better assess any structures that were not optimally viewed on the initial examination. Such practice has been demonstrated to detect up to $45 \%$ of fetal anomalies that had not been identified during the initial standard sonogram. ${ }^{30}$ Although every 20-week fetal anatomical survey demands careful evaluation, particular care must be undertaken to perform "targeted" sonographic assessment when there is a particularly high a priori risk of an anomaly (for example, elevated Down Syndrome serum risk, elevated maternal serum AFP, family history of congenital heart malformations, etc.); nevertheless, even in cases of elevated risk, anomalies can be missed. ${ }^{12}$ Another possible remedy employs the adage "two minds are better than one". It is always appropriate to consult with a colleague when needed (especially if the reading physician is in a group practice) when evaluating the normality or non-normality of a visualized structure. If a physician is in a solo practice, it may be prudent to send patients for a second opinion study; although some may describe this process as excessive, at the very least it will demonstrate the physician's thoroughness and thoughtfulness when it comes to patient care, to evaluate the fetal anatomical structures, and potentially to minimize the risk of an "imagined" anomaly. ${ }^{29}$ Lastly, in an ever-evolving field, it behooves the physician and sonographer team to remain as up-to-date as possible when it comes to continuing medical education (CME) in the field of OB-sonography. Physicians and sonographers can always benefit from attending virtual or in-person lectures and/or conferences from time to time: these events provide opportunities for direct learning as well as discussion and consultation with colleagues. Regular and effective auditing of cases within an ultrasound unit can also be beneficial, identifying if perception/interpretation errors are knowledge-based, which could benefit from further education and training. ${ }^{6}$ In addition to the benefits described in the previous section, another added value of having an AIUM-accredited practice is the mandatory CME requirements, which not only "forces" the provider(s) to stay informed on the current literature, but also demonstrates to patients and third parties that an ultrasound unit/practice maintains the most current standards in pregnancy and fetal evaluation. ${ }^{18}$

\section{"Take Home" Points}

- Understand the difference between perception and interpretation errors and their implications

- Ultrasound will always have a limited sensitivity to detect fetal anomalies

- When in doubt, physicians should not hesitate to re-scan patients themselves

- Order follow-up or second opinion sonograms when needed

- Perform "targeted" ultrasound examinations for high-risk patients

- Stay up to date with $\mathrm{CME}$, lectures, conferences

- Self-audit cases within the ultrasound unit.

\section{Communication/Documentation Errors}

Perhaps the most important (and controllable) errors can occur with communication and documentation. Communication can be divided into two aspects: (1) How the reading physician and sonographer communicate with the patient, and (2) How the reading physician communicates with the referring provider.

The majority of ultrasound examinations, thankfully, result in normal findings and eventual outcomes, whether it be a viability check, detailed anatomical survey, or a third-trimester interval growth examination. However, as was reviewed earlier, with ever-improving ultrasound technology, there is an increased expectation on the part of the patient and general public that a prenatal ultrasound should be able to diagnose all anatomic anomalies or genetic syndromes. ${ }^{11}$ The pregnant patient should be made aware not only of the limitations of prenatal ultrasound (for example, what it can and cannot or may not diagnose) but also of the chances of false-negative or false-positive findings. ${ }^{31}$ What is paramount is that the interpreting physician communicates with the patient that despite tremendous advances in diagnostic medicine over the past few decades, the ability of medicine to improve outcomes is limited: no one can guarantee a "perfect baby". It should be discussed that even in the absence of risk factors, a patient begins pregnancy with a $3 \%$ risk of birth defects. ${ }^{32}$ With that concept in mind, that patients understand the differences in types of examinations is also important: How often have practitioners been asked by patients at a follow-up 36-week growth ultrasound whether or not the fetus looks "perfectly healthy?" It should be explained to patients that there are differences in types of ultrasound examinations, for example, a follow-up interval growth ultrasound at 36 weeks does not evaluate the anatomy even remotely to the extent that the 20 -week comprehensive anatomy does. Keep in mind that most patients do not know these differences, and without counseling, can assume that all ultrasound scans carry the same potential for the diagnosis of any abnormality during the pregnancy. The patient should ideally possess reasonable expectations at the time of each ultrasound examination. Documentation of these conversations is beneficial as well (for example, "the results and limitations of ultrasound were discussed with the patient...").

How potential abnormal findings are shared with the patient is vitally important, as many malpractice cases do not arise from a knowledge gap or skill deficit, but rather from inadequate counseling. ${ }^{15}$ In most practices, especially Maternal-fetal Medicine Units, ultrasound findings are discussed with the patient in a face-to-face manner at the time of diagnosis. This provides the opportunity for the patient to ask questions directly to the physician, and to have the chance to discuss further options (e.g., genetic counseling, diagnostic testing, follow-up ultrasound, 2nd opinion, etc.). From an ethical standpoint, this puts patient autonomy into clinical practice: (1) Disclosure by the physician to the patient of adequate information about the patient's clinical condition and management, (2) Understanding of that information by the patient, and (3) A voluntary decision by the patient to authorize or refuse clinical management. ${ }^{33}$ As some lawsuits have resulted from failure to disclose to the patient all medical aspects of their case, the maternal-fetal medicine specialist should clearly define his or her role in the patient's care. Sometimes the specialist is performing the ultrasound for antenatal diagnosis only, whereas other times an additional consultation is provided, and/or the patient is co-managed by the specialist along with the primary provider. $^{8}$ 
Other practices that are more Radiology-based do not have face-to-face contact with the patient but will send a finalized report directly to the referring physician. Regardless of the method of communication with the patient, in the event of a fetal anomaly or any sonographic issue with the potential to impact clinical care, the reading physician is responsible for communicating these findings directly to the referring provider, and in a timely manner. Per the AIUM, communication "may be verbal or electronic, provided the means of conveyance complies with all applicable federal, state, and local privacy laws and provides acknowledgment that the communication was received". ${ }^{34}$ Errors in this type of communication represent a common allegation in lawsuits, and moreover, when this communication is not documented (date, time, name of person spoken to, what was discussed), the radiologist risks losing a lawsuit if adverse or unexpected clinical outcomes occur. ${ }^{24}$

Careful, thoughtful, and thorough documentation is by far the most effective tool in preventing litigation. In addition to documenting any communication involving patients or their referring providers, the interpreting physician must document anything that was seen (or unseen, if pertinent) at the time of evaluation, as well as provide a finalized ultrasound report to the referring provider. What Dr. Sanders wrote over 20 years ago remains applicable today-"Absence of documentation is considered equivalent to missing a lesion". ${ }^{35}$ It is imperative that the interpreting physician properly counsel the patient and document the findings and clinical information. This is especially important when certain views of the embryo or fetus are not optimally seen; discussions and recommendations for follow-up imaging should take place and be documented in the report. ${ }^{15}$ The AIUM has published practice parameters as a standard for the documentation of the ultrasound examination (Box 3). ${ }^{34}$ This provides guidance for documenting the general ultrasound examination and final ultrasound report, reporting nonroutine results, and reporting ultrasound-guided procedures (e.g., chorionic villus sampling, amniocentesis, fetal transfusion, etc.). ${ }^{34}$ Finalized ultrasound reports should be completed and sent to the referring practitioner promptly, documenting all findings and communication that took place. The AIUM has maintained that a permanent record of both the images and the interpretation of the ultrasound be recorded in a retrievable format. ${ }^{8}$ If still-frame images and/or cine clips are used, the archived images should contain the following: $:^{34}$

- Patient's name and other identifying information

- Facility's identifying information

- Date and time of the ultrasound examination

- Output display standard (thermal and mechanical index)

- Label of the anatomic location and laterality, when appropriate

- Image orientation when appropriate.

\section{“Take Home" Points}

- Counsel patients on the limitations of ultrasound-No one can guarantee a "perfect baby"

- Educate patients on the different types of ultrasound examinations

- Clearly define your role in the patient's care

- Counsel patients on abnormal findings, suggest follow-up examinations or tests when appropriate and communicate findings and recommendations to the primary provider in a timely manner

Box 3: Documentation of the Ultrasound Examination ${ }^{34}$

The final report* should include but is not limited to the following demographic components:

- Patient's name and other identifying information

- Name of the ordering provider

- Location of the ultrasound facility and contact information

- Relevant clinical information, including the indication for the examination and/or current version of the appropriate ICD code

- Date and time of the ultrasound examination

- Specific ultrasound examination performed

- If endocavitary techniques are used, the method should be specified.

The body of the report should include a description of the examination, including the following components:

- A description of the studies and/or procedures performed

- Comments on the components of the examination as outlined in the relevant practice parameter(s)

- A description of any contrast media and/or pharmaceuticals used (including route of administration and dose, when applicable)

- Additional medications, catheters, or devices used should be indicated

- Any significant patient reaction or complication should be documented

- Anatomic measurements (For example, fetal biometry), as appropriate, and measurement of abnormal structures or organs, if taken

- A description of examination findings, using appropriate anatomic and ultrasound terminology (use of acronyms and abbreviations should be avoided).

The concluding statements or summary of the report should include these components:

- An impression, conclusion, or summary statement

- A specific diagnosis or differential diagnosis, if appropriate

- A recommendation for follow-up studies, if clinically applicable

- An accounting of any failure to include standard views or other necessary components (as listed in the appropriate practice parameter)

- If prior relevant imaging studies were reviewed, a statement of comparison should be included

- Details concerning any provider-to-provider communication in cases in which a delay in communication may have an adverse effect on the patient's outcome.

${ }^{*}$ A signed final report of the ultrasound findings and impression should be included in the patient's medical record and is the definitive documentation of the study 
- Review the AIUM practice parameters on ultrasound reporting

- Complete and send finalized ultrasound reports to primary providers, documenting all findings and communication that took place

- Keep a permanent record of both images and reports in a retrievable format.

\section{Conclusion}

Obstetrics and Gynecology remains one of the more high-risk specialties when it comes to malpractice lawsuits, and as a component of the field, OB/GYN ultrasound has not been spared. This review aimed to describe the most common errors in OB/GYN ultrasound leading to litigation. By using the categorizations described, it is hoped that the reader will gain an appreciation for the different types of possible errors: (1) technical/procedural, (2) perception/interpretation, and (3) communication/documentation. The overwhelming majority of these errors are preventable, but their avoidance involves, among other strategies: adequate training and continuing education, knowledge of the guidelines, ample patient counseling, effective communication with referring providers, and meticulous documentation. Physicians and sonographers alike need not adopt a policy of defensive medicine, once they are equipped with an "ounce of prevention."

\section{References}

1. Meire HB. Ultrasound-related litigation in obstetrics and gynecology: the need for defensive scanning. Ultrasound Obstet Gynecol 1996;7(4):233-235. DOI: 10.1046/j.1469-0705.1996. 07040233.x

2. Jena $A B$, Seabury $S$, Lakdawalla $D$, et al. Malpractice risk according to physician specialty. N Engl J Med 2011;365(7):629-636. DOI: 10.1056/NEJMsa1012370

3. Goergen S, Schultz T, Deakin A, et al. Investigating errors in medical imaging: lessons for practice from medicolegal closed claims. J Am Coll Radiol 2015;12:988-997. DOI: 10.1016/j.jacr.2015.03.025

4. Schaffer AC, Jena AB, Seabury SA, et al. Rates and characteristics of paid malpractice claims among US physicians by specialty, 1992-2014. JAMA Intern Med 2017;177(5):710-718. DOI: 10.1001/jamainternmed.2017.0311

5. Domingues AP, Belo A, Moura $P$, et al. Medico-legal litigation in obstetrics: a characterization analysis of a decade in Portugal. Rev Bras Ginecol Obstet 2015;37(5):241-246. DOI: 10.1590/SO100-720320150005304

6. Anumba DO. Errors in prenatal diagnosis. Best Pract Res Clin Obstet Gynaecol 2013;27(4):537-548. DOI: 10.1016/j.bpobgyn.2013.04.007

7. Studdert DM, Mello MM, Sage WM, et al. Defensive medicine among high-risk specialist physicians in a volatile malpractice environment. JAMA 2005;293(21):2609-2617. DOI: 10.1001/jama.293.21.2609

8. Chervenak FA, Chervenak JL. Medical legal issues in obstetric ultrasound. Clin Perinatol 2007;34(2):299-308. DOI: 10.1016/j. clp.2007.03.007

9. Sanders RC. Legal suits involving ultrasound. Ultrasound Med Biol 1983;(Suppl. 2):27-32. DOI: 10.7863/jum.1983.2.3.r26

10. Bundy AL, Jones TB. Guidelines for obstetrical scanning and reporting: the legal necessity. J Ultrasound Med 1985;4(9):483-484. DOI: 10.7863/jum.1985.4.9.483

11. Sanders RC. Changing patterns of ultrasound-related litigation: a historical survey. J Ultrasound Med 2003;22:1009-1015. DOI: 10.7863/jum.2003.22.10.1009

12. Milunsky A. Obstetrics, genetics, and litigation. Acta Obstet Gynecol Scand 2021;100:1-9. DOI: 10.1111/aogs.14095

13. AIUM-ACR-ACOG-SMFM-SRU Practice parameter for the performance of standard diagnostic obstetric ultrasound examinations. J Ultrasound Med 2018;37(11):E13-E24. DOI: 10.1002/jum.14831
14. Committee on Practice Bulletins - Obstetrics and the American Institute of Ultrasound in Medicine Practice bulletin no. 175: ultrasound in pregnancy. Obstet Gynecol 2016;128(6):e241-e256. DOI: 10.1097/AOG.0000000000001815

15. Shwayder JM, Copel JA, Stohl H. Coding and legal issues in obstetric and gynecologic ultrasound. Obstet Gynecol Clin N Am 2019;46:853-862. DOI: 10.1016/j.ogc.2019.07.012

16. AIUM practice parameter for the performance of detailed secondand third-trimester diagnostic obstetric ultrasound examinations. J Ultrasound Med 2019;38(12):3093-3100. DOI: 10.1002/jum.15163

17. American Institute of Ultrasound in Medicine. AIUM Physician Training Guidelines. American Institute of Ultrasound in Medicine 2021. Available from: http://www.aium.org/resources/ptGuidelines.aspx [accessed 05-05-21].

18. American Institute of Ultrasound in Medicine. AIUM Ultrasound Practice Accreditation. American Institute of Ultrasound in Medicine 2021. Available from: http://www.aium.org/accreditation/ accreditation.aspx [accessed 05-05-21].

19. James AE, Fleischer AC, Thieme G, et al. Diagnostic ultrasonography: certain legal considerations. J Ultrasound Med 1985;4:427-431. DOI: 10.7863/jum.1985.4.8.427

20. Garner B. Black's law dictionary. 7th ed. St. Paul (MN): West Group 1999.

21. AIUM practice parameter for the performance of limited obstetric ultrasound examinations by advanced clinical providers. J Ultrasound Med 2018;37(7):1587-1596. DOI: 10.1002/jum.14677

22. ACOG committee opinion no. 723: guidelines for diagnostic imaging during pregnancy and lactation. Obstet Gynecol 2017; 130(4):e210-e216. DOI: 10.1097/AOG.0000000000003049

23. Wu KH, Cheng HH, Cheng FJ, et al. An analysis of closed medical litigations against the obstetrics departments in Taiwan from 2003 to 2012. Int J Qual Health Care 2016;28(1):47-52. DOI: 10.1093/intqhc/mzv093

24. Pinto A, Brunese L. Spectrum of diagnostic errors in radiology. World J Radiol 2010;2(10):377-383. DOI: 10.4329/wjr.v2.i10.377

25. Hassan M, Chitty L, Reardon H. Wrongful birth: clinical settings and legal implications. Semin Fetal Neonatal Med 2014;19(5):312-316. DOI: 10.1016/j.siny.2014.08.006

26. Brezinka C. Obstetric ultrasound and the many faces of malpractice lawsuits. Ultrasound Obstet Gynecol 2000;16:207-209. DOI: 10.1046/j.1469-0705.2000.00267.x

27. Levi S. Ultrasound in prenatal diagnosis: polemics around routine ultrasound screening for second trimester fetal malformations. Prenat Diagn 2002;22(4):285-295. DOI: 10.1002/pd.306

28. Sileo FG, Finarelli A, Contu G, et al. Ultrasound screening for fetal anomalies in a single center: diagnostic performances twenty years after the Eurofetus Study. J Matern Fetal Neonatal Med 2021:1-8 (Online ahead of print). DOI: 10.1080/14767058.2021.1911994

29. Macones AJ, Lev-Toaff AS, Macones GA, et al. Legal aspects of obstetric sonography. Am J Roentgenol 1989;153(6):1251-1254. DOI: 10.2214/ajr.153.6.1251

30. Byrne JJ, Morgan JL, Twickler DM, et al. Utility of follow-up standard sonography for fetal anomaly detection. Am J Obstet Gynecol 2020;222:615.e1-615.e9. DOI: 10.1016/j.ajog.2020.01.001

31. Mavroforou A, Mavrophoros D, Koumantakis E, et al. Liability in prenatal ultrasound screening. Ultrasound Obstet Gynecol 2003;21:525-528. DOI: 10.1002/uog.168

32. Chervenak FA, McCullough LB, Brent RL. The perils of the imperfect expectation of the perfect baby. Am J Obstet Gynecol 2010;203(2):101-105. DOI: 10.1016/j.ajog.2010.01.058

33. Chervenak FA, McCullough LB. Ethics, an emerging subdiscipline of obstetric ultrasound, and its relevance to the routine obstetric scan Ultrasound Obstet Gynecol 1991;1(1):18-20. DOI: 10.1046/j.1469-07 05.1991.01010018.x

34. AIUM practice parameter for documentation of an ultrasound examination. J Ultrasound Med 2020;39(1):E1-E4. DOI: 10.1002/jum.15187

35. Sanders RC. Legal problems related to obstetrical ultrasound. Ann NY Acad Sci 1998;847:220-227. DOI: 10.1111/j.1749-6632.1998.tb08943.x 